\title{
The Context of Operations as the basis for the Construction of Ontologies of Employment Pro- cesses
}

\author{
Iryna Zavuschak \\ PhD-student of the Department of Information Systems and Networks, \\ Lviv Polytechnic National University Lviv, 79013, Ukraine \\ Email: iryska2009@ukr.net \\ Yevhen Burov \\ Professor of the Department of Information Systems and Networks, \\ Lviv Polytechnic National University Lviv, 79013, Ukraine \\ Email: yevhen.v.burov@1pnu.ua
}

Received: 18 August 2017; Accepted: 16 October 2017; Published: 08 November 2017

\begin{abstract}
The growing tempo of changes in world's economics emphasizes the ability of enterprise to adapt to changes in business environment as an important competitive advantage. Adaptive intelligent enterprises, which use knowledge models for adaptation, form basis of cognitive economics. Currently those intelligent enterprises are utilizing ontological modeling for knowledge representation. In this article, a method for building ontology based on analysis of context of business operations is proposed. The application of this method is described in detail using recruitment area business process as example. The developed method of ontology construction allows for continuous ontology modification and update and accentuates the analysis of implicit context information.
\end{abstract}

Index Terms - Context, ontology, recruitment, business process, intelligent enterprise

\section{INTRODUCTION}

The problem of employment in Ukraine continues to be relevant. The employment of young highly skilled specialists and the development of human resource potential of enterprises directly affect the level of competitiveness of both individual regions and the state as a whole. Of the total number of unemployed citizens, 30\% are young people under the age of 35 . But there is also shadow employment, which is not taken into account by official statistics. Young specialists are the future of our country, which should be demanded (but, unfortunately, not so) in the modern labor market.

This article consists of five sections and conclusion. In introduction we briefly highlight the importance of achieving efficient recruitment processes for economy. In second section, we review the current state of research in area of intelligent enterprise related to recruitment processes. Third section is dedicated to investigation of ontological modeling as a basis for our research. In next section we present a method for building process ontology based on contextual situations. The last section provides a detailed example of ontology construction using proposed method for recruitment processes in Ukraine.

\section{RELATED WORKS}

The increase of complication, rates of changes of business-environment and level of globalization of world economy results in the necessity of permanent adaptation of structure and maintenance of business processes of enterprise to the hurrying state of businessenvironment. In these terms an important competitive edge is ability it is automated to make decision on the basis of knowledge about a subject domain. Realization of technologies of the use of knowledge in business processes found the reflection in conception of intellectual enterprise that sees the main subsystems of enterprise as services built on knowledge $[1,2]$.

This conception got further development in a concept "cognitive economy" that uses the informative systems capable semantically to interpret the got businessinformation. For this purpose use difficult linguistic algorithms that give an opportunity to educe and analyze semantic dependences and set forth knowledge on the basis of arrays business-given [3].

The considerable volume of researches in industry of cognitive economy is today sent to the booty of knowledge from business-information, id est exposure of dependences, rules and tendencies of behavior, grouping and classification of objects [4]. The knowledge got as a result of such analysis use in the systems of support making decision that will realize flexible, analytical and adaptive business processes [5]. At the same time, task of the use of knowledge and methods of analytic businessgeometry for support of the automated acceptance of 
decisions in operative activity of enterprise largely it remains unsolved.

Employment is a system of organizational, economic and legal measures aimed at ensuring employment of the population. In a broad sense, employment brings together all forms of work that do not contradict the law (including independent self-employment), including individual labor, entrepreneurship, farming, etc. In the narrow sense, employment refers to such forms of labor activity, which are established with the assistance of state bodies or nongovernmental organizations on the basis of licensing. It must be taken into account that the notion of employment is narrower than the notion of employment, namely, employment is preceded by employment and is its most important guarantee [18].

Actuality of the decision of the problem of creating intelligent information systems for the field of employment stems from the relevance of the problem of the effective use of labor resources and the realization of creative potential of citizens. The solution of this problem involves reconciling the interests of searchers and employers with the use of many as quantitative and qualitative criteria, which in turn makes prospective application of methods of artificial intelligence and knowledge engineering.

\section{The UsE OF ONTOLOGICAL DeSIGN Is ON AN INTELLECTUAL ENTERPRISE}

The generally accepted approach to formalized presentation of knowledge at an intellectual enterprise today is the use of ontologies. In [6], ontology is defined as a formal model of a certain conceptualization of a subject area. Such a model contains the definition of the entities of the subject domain $\mathrm{E}$ and the relations $\mathrm{R}$ between them, the constraints and axioms A:

$$
O n=(E, R, A)
$$

Building intelligent systems based on ontologies avoids re-conceptualizing the subject area and achieves a unified understanding and representation of all objects in this area, which reduces the use of resources and the number of conceptualization errors.

One of the advantages of ontologies is their suitability for solving such important tasks as structuring knowledge and their reuse. In this case, the general scheme (presentation and use of knowledge) is uniquely determined for agents working with it as a shared resource, and this resource can be distributed among agents, as well as repeatedly used.

To date, the ontology of top-level business processes has been developed and the issue of their use for solving business intelligence problems [7, 8] has been considered. The question of developing methods for constructing and maintaining quality ontologies remains open to ontologies of specific application areas. [9, 10] defines the following criteria for the quality of ontology as completeness, integrity, lack of redundancy and the possibility of expansion and modification.
Typically, ontology is created as a result of the analysis of a specific knowledge body provided, for example, as a set of texts on the subject of a specific domain, its standards [11], or as a result of the analysis of tasks of system [12]. Complexity of construction, support of ontologies and their quality depend on the chosen methodology of creation and the body of knowledge, which is the basis. In the case of building ontology of business processes of a particular subject field, it is expedient to select the subject of analysis of the individual business process operations and their relationships. Such business operations are often operations of decision-making automation which contributes to improving the efficiency of their implementation.

An important task to be solved when constructing ontology for an intellectual enterprise is the proper understanding and use of the context, including implicit data, information and knowledge [13] at all stages of the business process. The lack of explicit definition and processing of the context and its reflection on the ontology is considered one of the reasons for failures in the construction of intellectual systems [14]. Detecting contextual entities and relationships is aimed at achieving completeness and lack of redundancy in ontology.

The purpose of the article is to develop a method for constructing the ontology of the subject industry based on the analysis of the context of operations on the example of business processes in the employment field, performed in the center of employment.

\section{METHOD CONSTRUCTION OF ONTOLOGY ON THE BASIS ANALYSIS OF CONTEXTS OF BUSINESS OPERATIONS}

The complexity of solving the problem of building an ontology based on the analysis of operations of the business process stems not only from the large number and complexity of business operations itself, but also the dynamic nature of these operations, which may depend on the state of the environment, the results of the previous operations, and the available knowledge of execution Similar operations in the past.

To isolate the context of operations (tasks) in [15] the concept of context ontology, that is, ontology containing objects and relations relevant to a problem are solved at the given time, is introduced. Thus, context-based ontology is determined by the specific data set of the operation and various context-based ontologies can exist for different sets of such data. The construction of context-based ontologies for an operation involves identifying all the possible circumstances, constraints and options for performing this operation for the various data sets and environment states, and is not a difficult task. As a rule, an intelligent system works with a single ontology, so the resulting context ontologies must be integrated into one (On) ontology, which involves solving the problems of ensuring integrity, eliminating possible contradictions and ensuring the quality of the resulting ontology [19]. 
Solving the task of constructing an ontology based on the analysis of operational contexts is advisable to start with the creation of a business process model using one of the modeling language processes. As a result, the structure of the process, its components of business operations and the links between them are determined.

The second step is to analyze each business transaction. Determine:

A) The entities and their attributes that are involved in the operation. If possible, refer them to types already defined in the general ontology $(\mathrm{On})$. If objects of these types are not present on ontology, they add to the ontology new types of objects or attributes to existing ones.

B) The relation and their attributes are relevant to the operation. Similarly to item (a), they refer to known types of relationships, or create new types of relationships.

As a result of the analysis of business operations, they receive ontology of this operation $O n_{o p} \subseteq O n$

The entities and relationships reflected in $O n_{O p}$ ontology determine the primary data necessary to complete a business operation. At the same time, in addition to the explicit data formulated in the concrete facts of the model, it is often necessary to obtain additional information for the implementation of the process. This information exists in the context of explicitly specified model facts and their attribute values, and can be obtained by creating additional queries to the system knowledge base, as well as to external databases. We shall consider such data the context of operation. As a result of the analysis of the context of the operation, contextual ontologies are formed.

To construct context-based ontologies, it's advisable to identify situations that may arise during a business transaction. Such situations are defined in the context of the operation that is, using the $O n_{O p}$ ontology entities and attitudes. The set of situations is determined by the expert. Each situation is formalized in the form of an ontological model of the situation as a triple:

$$
\operatorname{Sit}=\left(\mathrm{Sig}_{s t}, O n_{s t}, S A c t_{s t}\right),
$$

where $\mathrm{Sig}_{s t}$ - signature of the situation, $\mathrm{On}_{s t}$ - ontology of the situation, $S A c t_{s t}$ - set of actions. Signature of a situation is a condition specified on the facts of the facts base. If this condition is met, then it is believed that the situation is taking place and actions from $S A c t_{s t}$ must be performed.

Ontology $O n_{s t} \subseteq O n$ - displays the information needed to make a decision about the situation. It may contain elements that are not present in ontology $O n_{o p}$. This, in turn, will require additional information.

$S A c t_{s t}$ actions are specified in the ontology in the registry of possible actions. Similar to $O n_{o p}$, ontology $O n_{s t}$ also integrates with $O n$ ontology.

A common approach to preserving and processing contextual data [16] is to tie them to entities or attitudinal relationships. For example, consider the "user context" or "context of the location." The advantage of this approach is to reuse the ontological knowledge associated with these objects for different situations.

One of the problems of constructing an ontology based on the analysis of situation contexts is the large number of possible situations and their models in the knowledge base. In this case, some models of situations can be used repeatedly, with different operations of the business process. The obvious solution to this problem is to associate a set of situations with a business operation. But in this case, the analysis of the relevance of the situation, especially if it requires recourse to external sources of information, will take a considerable amount of time.

It is possible to reduce the complexity of the analysis by using the situation keys. The key is the tuple

$$
\text { Key }_{s t}=(\text { Sigkey,TSit })
$$

which contains a set of conditions (signatures) Sigkey, and a situation identifier or a tree of situations TSit. Signature of the key is specified on $O n_{o p}$ ontology elements and its verification does not require additional information retrieval. If the key signature value is true, then the root situation from the specified decision tree is considered to be used to clarify the current situation by generating requests for contextual data and conducting additional verifications.

\section{ANALySIS OF BUSINESS PROCESSES OF CUSTOMER SERVICE AT THE EMPLOYMENT CENTER AND BUILDING ONTOLOGY}

Employment is a system of organizational, economic and legal measures aimed at ensuring employment of the population. In a broad sense, employment brings together all forms of labor activity that do not contradict the law (including independent self-employment), including individual labor, entrepreneurship, farming, etc. In the narrow sense of employment refers to such forms of employment, which are established with the assistance of state bodies or non-governmental organizations on the basis of licensing. It must be taken into account that the notion of employment is narrower than the concept of employment, namely, employment is preceded by employment and is its most important guarantee [17].

Actuality of the decision of the task of creating intelligent information systems for the field of employment stems from the relevance of the problem of the effective use of labor resources and the realization of creative potential of citizens. Solving this problem involves reconciling the interests of searchers and employers with the use of many as quantitative and qualitative criteria, which in turn makes prospective application of methods of artificial intelligence and knowledge engineering.

\section{A. General structure and process model}

Activities of the Employment Center are submitted as a set of interrelated processes and operations that are carried out independently. The main process is the customer service process. As a result of this process, written 
recommendations on employment, skills development, etc. are formed. Assistive processes are the processes of forming and maintaining a vacancy database, professional information, and selection.

The client addresses to the employment center and fills in a specified form with information about him and defines the essence of his visit. The employee of the employment center (dispatcher) analyzes the client's request and, depending on its content, determines the following actions. Such actions may include the appointment of an interview, the provision of background information on job search opportunities and advanced training. During an interview, the employee checks the information provided by the client, clarifies it, and offers the following steps for employment. These actions are reflected in the written document - recommendations. Such actions can be, for example, interview with the employer, vocational guidance work or advanced training courses, focusing on community work. Upon completion of the interview, the Employment Center supervises the implementation of the recommendations. Information about the client, his request, the developed recommendations and control information are entered into the information system of the Employment Center. The main objects involved in the process of servicing unemployed citizens in the center of employment and the links between them is illustrated by a cooperation diagram (Figure 1).

The database of vacancies is formed on the basis of applications from employers. Each application for each vacancy defines employee requirements. The labor market analysis aims at identifying promising occupations and career development trends for clients. The results of the analysis are used to provide advice to clients on the change of profession or advanced training.

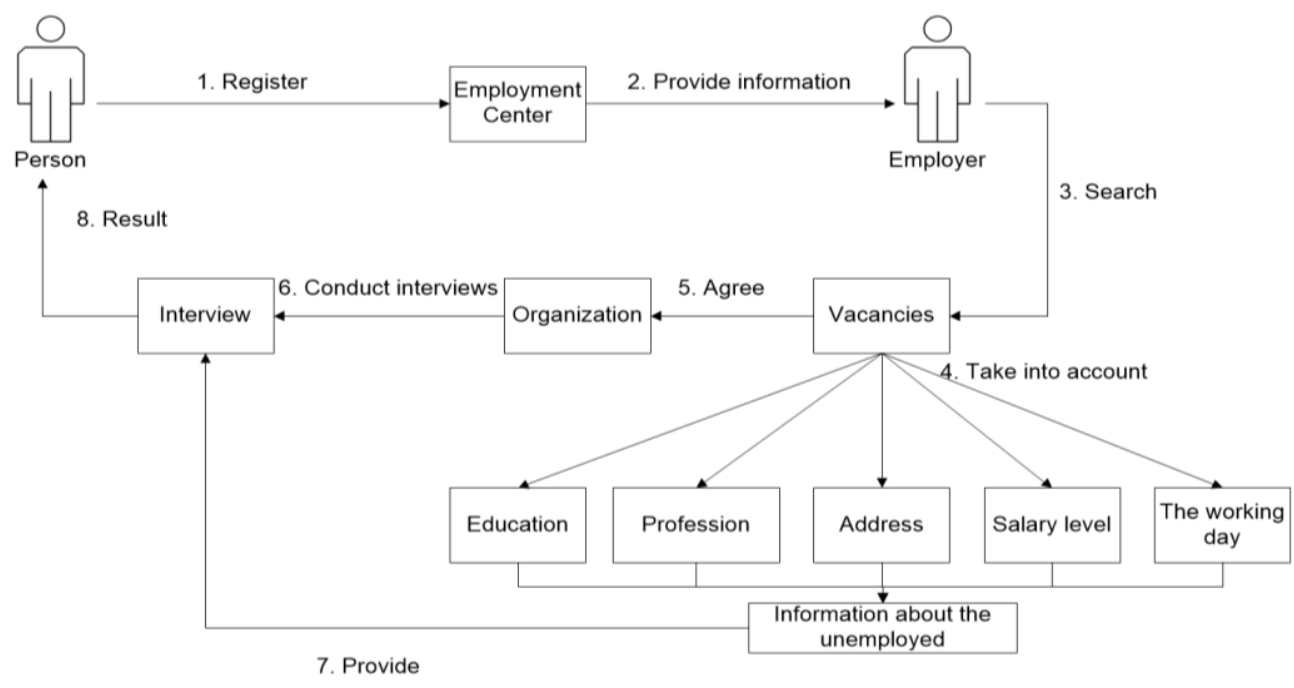

Fig.1 Diagram of cooperatives of the employment process

One way of presenting and analyzing contexts in business processes is context-sensitive graphs [15]. This graph is a directed acyclic graph with a unique input and output and sequentially-parallel organization of vertices associated with oriented arcs. The vertex can be used to represent action, context-dependent concept, recombination vertex or subgraph. The action corresponds to the executable method, the context-dependent concept - the concept that has implementation in this context, the recombination vertex - the general concept (the more abstract concept), the subgraph - the sequence of executable methods used in solving the problem. The relationship between the vertices shows the sequence of actions. If there are several different variants of such a sequence, these variants are closed by the recombination peak, which after the passage of the branch with the sequence fixes which branch is worked out. Context management is carried out in a dynamic mode during the task solution. It is based on fixing what contextual-dependent concept has been realized at the moment and, conversely, what procedure has already worked, freeing implementation and turning it into abstract elements.
Let's consider the process of employment in the form of a context-dependent graph (Fig. 2), the vertices of which are the processes through which every person who wants to find work through the employment service must pass and the ribs are operations performed by specialists of the basic employment centers at the service of the population. For each operation, we identified relevant information that defines the context of the operation and changes in the transition to other operations of the process. The process of employment with the employment service starts with a citizen's request for such a service, with the assistance of finding a suitable job.

Let's consider separate processes and operations of this process for the purpose of construction of ontology on the basis of contexts of individual operations.

\section{B. Customer registration}

In the first step of the process, the unemployed person is registered at the employment center. As a result of the registration process, the client receives a ticket from the manager for an appointment with a job search specialist. The main function of the specialist who performs the 
reference and dispatching functions is the distribution of the flows of the clients of the Center of Employment, depending on the purpose of the visit. The main functions of such a specialist are given in Table 1, and the registration process is illustrated by the diagram of Fig. 2

Table 1. Manager functions

\begin{tabular}{|l|l|}
\hline \multicolumn{1}{|c|}{ Function name } & \multicolumn{1}{|c|}{ Function content } \\
\hline $\begin{array}{l}\text { The purpose of the customer's request at } \\
\text { the Employment Center }\end{array}$ & $\begin{array}{l}\text { Finds the purpose of applying to the Employment Center } \\
\text { Distributes flows of clients, including employers, between specialists depending on the purpose of the } \\
\text { appeal. } \\
\text { Brings personal information to the database of the Unified Information and Analytical System (EIAS). }\end{array}$ \\
\hline $\begin{array}{l}\text { Determine the date and time of custom- } \\
\text { er reception by specialists }\end{array}$ & $\begin{array}{l}\text { Performs operations in the EIAS on the appointment of admissions to persons depending on the purpose } \\
\text { of the application, to a specialist in employment or other specialized departments. Issues a receipt with } \\
\text { the information on the reception number and the like. }\end{array}$ \\
\hline $\begin{array}{l}\text { Informing about the possibility of } \\
\text { independent job search }\end{array}$ & $\begin{array}{l}\text { Recommends that a person use materials in the sector of independent job search and the professional } \\
\text { information sector. }\end{array}$ \\
\hline
\end{tabular}

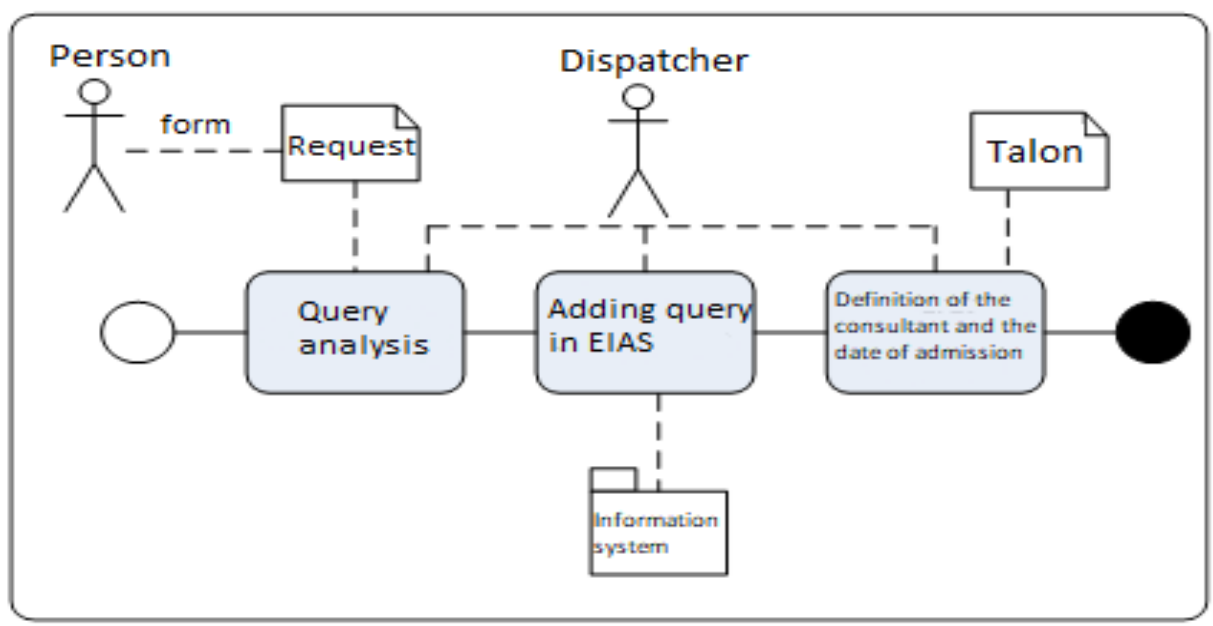

Fig.2. Chart of the client registration process

As a result of the analysis of the customer registration process, the ontology of this process is presented in ta- bles 2,3 . The essence and attitude are grouped by similarity features.

Table 2. The essence of the registration process

\begin{tabular}{|l|l|l|l|}
\hline \multicolumn{1}{|c|}{$\begin{array}{c}\text { A group of Essences or a } \\
\text { general Essence }\end{array}$} & \multicolumn{1}{|c|}{ Subgroup } & \multicolumn{1}{|c|}{ Essence } & Full name \\
\hline Person & & Client & ID number \\
\hline & $\begin{array}{c}\text { Employee } \\
\text { of the Employ- } \\
\text { ment Center }\end{array}$ & Dispatcher & Card number \\
\hline Document & & & Document ID, document type \\
\hline & & Job Request & Position, salary \\
\hline Information services & & $\begin{array}{l}\text { EIAS - Unified Information and Analyt- } \\
\text { ical System }\end{array}$ & Information about the client's request \\
\hline
\end{tabular}

Table 3. Relationship of the registration process

\begin{tabular}{|l|l|}
\hline \multicolumn{1}{|c|}{ Title of the relationship } & \\
\hline Form a request & Client, request \\
\hline Make a request to the system & Request, dispatcher, EIAS \\
\hline Appoint reception & Dispatcher, talon \\
\hline
\end{tabular}

In order to illustrate the context analysis of operations for ontology construction, consider an example of a situation that occurs during client registration. Working out such a situation allows improving the quality of customer service, but for its conduct it is necessary to obtain additional information from the context of the operation about the client.
The efficiency of a dispatch operation can be improved by analyzing the client's request for discrepancies. For example, if a client requests a post for which he does not qualify for his educational documents. To perform a check on the compliance of a client's qualification with its context, it is necessary to obtain information about the qualification certified by the corresponding certificates. 
In case of discrepancy between the request and the qualification available, the dispatcher informs the client and rejects the request. Additional essences and relationships with the client context and query are given in tables 4.5.

Table 4. Context essence of the registration process

\begin{tabular}{|l|l|l|l|}
\hline $\begin{array}{c}\text { A group of Essences or a } \\
\text { general Essence }\end{array}$ & Subgroup & \multicolumn{1}{|c|}{ Essence } & Attributes \\
\hline Document & & Request for qualification & Full name of the client \\
\hline & & Response to qualification request & Information about qualifications \\
\hline & & Result verification & Qualification compliance \\
\hline Information services & Information search system & Protocol appeal \\
\hline
\end{tabular}

Table 5. Context relations of the registration process

\begin{tabular}{|l|l|}
\hline \multicolumn{1}{|c|}{ Title of the relationship } & \multicolumn{1}{c|}{ Connects the essence } \\
\hline Form a request & Qualification Requests, Search Information System \\
\hline Get an answer & Search Information System, Response to Qualification Requests \\
\hline Check the qualifications & Request for employment (position), the answer to a request for qualifications \\
\hline
\end{tabular}

Similarly to checking the qualifications, for posts with special health requirements, it is advisable to formulate a request for databases of medical institutions where the client is registered and receive information about his state of health. If a customer's health condition is found to be inconsistent with the application, the dispatcher informs him and offers an alternative, for example, re-profiling.

\section{Formation of the vacancy database}

The vacancy database is created by employees of the employment center on the basis of applications from employers, which can be submitted in oral, written or electronic form. For each job, the employer defines the requirements for the employee (qualifications, work experience, education, age, health status, etc.) and their proposals (pay, social package, career opportunities and training, etc.). The employer's offer is usually limited. The vacancy database is used by employment center employees to find job offers. The essence and attitude of the process of forming the vacancy base are given in tables 6,7 .

Table.6. The essence of the process of forming a vacancy database

\begin{tabular}{|l|l|l|l|}
\hline $\begin{array}{l}\text { A group of Essences or a } \\
\text { general Essence }\end{array}$ & Subgroup & Essence & Attributes \\
\hline Organization & & Employer & Name, address, contact information. \\
\hline Person & & & Card number \\
\hline ployment Center & $\begin{array}{l}\text { Specialist interaction with em- } \\
\text { ployers }\end{array}$ & $\begin{array}{l}\text { Organization, position, salary, Requirements, } \\
\text { validity }\end{array}$ \\
\hline Vacancy (Employer's offer) & & Database of vacancies & List of vacancies \\
\hline Information services & & \\
\hline
\end{tabular}

Table 7. Relationship of the process of forming the vacancy database

\begin{tabular}{|l|l|}
\hline Title of the relationship & Connects the essence \\
\hline Form a proposal & Organization, vacancy \\
\hline Add a job to the system & Job vacancies, specialist for engagement with employers, job vacancies database \\
\hline
\end{tabular}

An additional analysis of the context of employers will improve the quality of job placement. In particular, the employment center can start to rank employers on employee reviews, recording both the benefits and the dis- advantages of each employer. This will result in the ontology of the new entities and relationships presented in Tables 8, 9 .

Table 8. Contextual essences of the process of forming the vacancy database

\begin{tabular}{|l|l|l|l|}
\hline \multicolumn{1}{|c|}{$\begin{array}{c}\text { A group of Essences or a } \\
\text { general Essence }\end{array}$} & \multicolumn{1}{c|}{ Subgroup } & Essence \\
\hline Organization & & Employer & List of advantages and disadvantages, rating \\
\hline Person & $\begin{array}{c}\text { Employee of the Em- } \\
\text { ployment Center }\end{array}$ & Analyst & Card number \\
\hline Document & & Feedback about the employer & Author, date, advantages, disadvantages, rating \\
\hline Information services & & Employers Database & Protocols of interaction \\
\hline
\end{tabular}

Table 9. Context relations of the process of forming the vacancy database

Title of the relationship Work feedback
Connects the essence

Employer feedback, analyst, Employers Database 


\section{Interview with specialist of employment center}

The actions of the employment specialists (personal consultants) are aimed at identifying the needs, intentions and wishes of the client, ascertaining the professional characteristics important for his employment, informing the client about the available vacancies, performing the search and recruitment of the client, developing joint actions of the client and specialists of the Employment Centers, aimed at accelerating its employment, the disclosure of employment opportunities for a particular client, the formation of motivation for the client to persistent job search And participation in activation measures aimed at accelerating employment.

As a result of an employment interview (personal consultant) in conjunction with a client, on the day of making a decision on the registration of a person as unemployed, develops Individual written recommendations on the promotion of employment. In the future, during interviews with a person, analyzes the state of implementation of the recommendations and, if necessary, complements the new ones. Declares responsibility for non-compliance with the recommendations.

If job seekers during the reception chosen job, employment specialist calling for representative of the employer and finds out if the chosen workplace is free, and coordinates the opportunity to interview with the client. If the employer agrees to an interview, the employment specialist informs him about meeting and sends unemployed to the interview.

Interviewing is the main form of interaction of a specialist with a job seeker in the process of providing services. Based on the principles of individualization and targeting of work with the unemployed, a specialist of the employment center (personal consultant) during the interview should collect labor data, analyze the reasons for the loss of work by the client, identify his needs, intentions and objectives for employment, jointly choose the most effective way to work and Help overcome possible obstacles and difficulties in achieving the goals set. Important aspects of the interview are the formation of motivation for a client to find a job, self-confidence, perseverance and self-esteem, the sense of expediency of cooperation with the state employment service. As a result of a well-conducted interview, clients should develop strategies for job search and apply measures that will speed up seeker's job search.

In the course of an interview, in order to organize effective cooperation with the client in finding and recruiting a specialist, you need to find out in more detail:

- What factors are decisive for employment, including the expected salary, the nature of labor (mental, physical, creative, individual, teamwork, etc.), working conditions, career prospects, desired transport availability, working conditions?

- By what specialty, in addition to the previous job, he can work?

- Can the client agree to work not on the specialty, under what conditions?

- What circumstances led to the release of the client?

- Which, in his opinion, is the main reason that he cannot be employed?

- How was the independent job search?

- What are the typical and important features of a client?

- What are the possible restrictions of the client on the state of health, family status, and religious beliefs?

Registered unemployed persons, in accordance with clause 3 of Part 2 of Article 44 of the Law of Ukraine "On Employment of the Population", are obliged to comply with written individual recommendations on the promotion of employment, in particular, to take part in activities related to the promotion of employment protection of the population.

In the event of non-compliance with the recommendations on the promotion of employment, the duration of the payment of unemployment benefits is reduced to 90 calendar days in accordance with paragraph 5 of clause 5 of Article 31 of the Law of Ukraine "On Compulsory State Social Insurance Against Unemployment"

The measures related to the promotion of employment, which are included by the specialist of the Employment Center to the written individual recommendations on the promotion of employment, can be attributed to:

- $\quad$ Visiting the employment center, in which the unemployed person is registered, in the time determined and agreed with him.

- Visiting an employer within 7 calendar days according to the issued referral for employment for suitable work.

- Visits by the employer within 7 calendar days in accordance with the issued referral for employment for public and other temporary work (in case if participation in such works is suitable work).

- Vocational training in the direction of the employment center for the acquisition and improvement of professional knowledge, skills and competences in the labor market (if suitable work is offered, it needs professional training).

In case of non-fulfillment by the unemployed of these recommendations, the employment specialist imposes sanctions in the form of reducing the duration of unemployment benefit payments. 


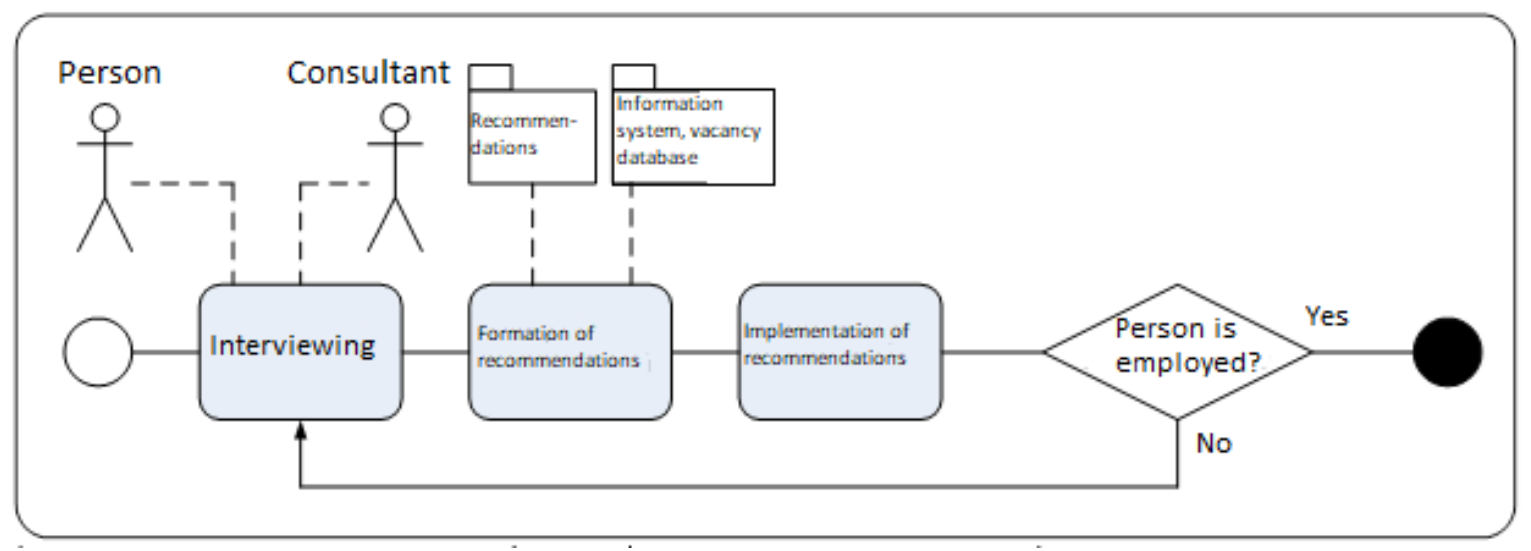

Fig.3. Diagram of the process of interviewing and trying to employment

The process of employment is illustrated by the diagram in Fig. 3. The client interviews with the consultant, which details the client's requirements for work and develops written recommendations. For the formation of the recommendation information from the vacancy data- base is used. If, as a result of their performance, the client failed to recruit, the interview is repeated and the recommendations are modified. All intermediate steps and their results are recorded in EIAS. The essence and attitude of the interview process are shown in tables 10, 11 .

Table 10. The essence of the interview process

\begin{tabular}{|l|l|l|l|}
\hline \multicolumn{1}{|c|}{$\begin{array}{c}\text { A group of Essences or a } \\
\text { general Essence }\end{array}$} & \multicolumn{1}{|c|}{ Subgroup } & \multicolumn{1}{|c|}{ Essence } & \multicolumn{1}{|c|}{ Attributes } \\
\hline Person & & & Full name \\
\hline & & Client & ID number \\
\hline Document & $\begin{array}{c}\text { Employee of the Em- } \\
\text { ployment Center }\end{array}$ & Employment Consultant & Card number \\
\hline Vacancy & & Recommendation & $\begin{array}{l}\text { Organization, position, term of reference, result } \\
\text { of application. }\end{array}$ \\
\hline Information services & & $\begin{array}{l}\text { Organization, position, salary, Requirements, } \\
\text { validity }\end{array}$ \\
\hline & & $\begin{array}{l}\text { EIAS - Unified Information and } \\
\text { Analytical System }\end{array}$ & History of appeal \\
\hline
\end{tabular}

Table 11. Relationship of the interview process

\begin{tabular}{|l|l|}
\hline \multicolumn{1}{|c|}{ Title of the relationship } & \multicolumn{1}{c|}{ Connects the essence } \\
\hline Interviewing & Client, consultant (date of conducting, recommendations) \\
\hline Formation of the recommendation & Client, consultant, recommendation. \\
\hline Implementation of the recommendation & Client, recommendation. \\
\hline
\end{tabular}

The quality of customer service can be greatly improved if you obtain additional information from the context of its request and develop recommendations based on it. For example, if a client is a scientist looking for a job, then having obtained information from his open databases about his work and previous projects, one can pick projects from a vacancies database on similar topics. This will add to the ontology new essences and relationships with the client and query contexts in tables 12 and 13.

Table 12. Context essences of the interview process

\begin{tabular}{|l|l|l|l|}
\hline \multicolumn{1}{|c|}{$\begin{array}{c}\text { A group of Essences or a } \\
\text { general Essence }\end{array}$} & \multicolumn{1}{c|}{ Subgroup } & \multicolumn{1}{c|}{ Essence } & \multicolumn{1}{c|}{ Attributes } \\
\hline Person & & Client & Scientific interests, list of publications. \\
\hline Vacancy & & Vacancies in scientific projects & Position, salary, expiry date \\
\hline Information services & & Services Search publications & \\
\hline
\end{tabular}

Table 13. Contextual relations of the interview process

\begin{tabular}{|l|l|}
\hline Title of the relationship & Connects the essence \\
\hline Search for posts & Consultant, Client, Publishing Services \\
\hline Determination of vacancies on the project & Consultant, database of vacancies \\
\hline
\end{tabular}




\section{E. Providing services of professional orientation}

Providing clients with services in the field of professional orientation is a separate operation, which, although it is not intended to directly employ a client, but increases its awareness and the ability to independently search for a job.

Services of professional orientation are provided to people in need, on a voluntary basis. Types and forms of vocational guidance services offered to a person are determined by the employee of the territorial office in agreement with the person.

\section{F. Providing services of professional information}

Professional information is to provide information about the work activity and its role in the professional Self-determination of the person, information on the state of the labor market, the content and prospects of the development of modern occupations and requirements for the person, the forms and conditions of mastering the professions, opportunities for professional qualification and career growth, Which will contribute to the formation of professional interests, intentions and motivation of a person to elect or change the type of work, profession, qualification, work.

This area is implemented in the professional information sector of the employment center by a specialist in professional information and provides for the following functions:

1. Information and consultation services for visitors to the employment center by providing primary information, assistance in using informational materials and engaging in informational counseling and / or career counseling activities.

2. Participation in the preparation and conducting of group (mass) information-consulting and / or vocational guidance activities.
3. Formation of the bank of normative, informational, professional and methodological materials.

Professional information services are provided in a group (mass) and individual forms.

\section{G. Providing services of professional counseling}

Professional counseling (professional counseling) is a vocational guidance service aimed at optimizing the professional self-determination of a person on the basis of identifying her individual psychological characteristics, peculiarities of life situations, professional interests, inclinations, health and taking into account the needs on the labor market.

\section{H. Providing services of professional selection}

Professional selection - professional guidance service, aimed at establishing the compliance of the person with the requirements of specific professions, positions. Of particular importance is the professional examination of occupations at high risk for the worker himself and for people around him.

Specialists in professional counseling conduct professional selection in two cases: when completing the training groups according to a certain profile of professional training and recruiting staff on request of employers.

The results of physical fitness training are recommended to those who by their individual psychological characteristics and professionally important qualities meet the requirements of the profession.

The procedure for the recruitment of staff on the order of employers is carried out taking into account the requirements specified by the employer in the application for employees submitted to the employment center. The essence and relation of the processes of professional orientation, informing and selection are presented in Tables 14, 15.

Table 14. The essence of processes of professional orientation, informing and selection

\begin{tabular}{|l|l|l|l|}
\hline \multicolumn{1}{|c|}{$\begin{array}{c}\text { A group of Essences or a } \\
\text { general Essence }\end{array}$} & \multicolumn{1}{c|}{ Subgroup } & \multicolumn{1}{c|}{ Essence } \\
\hline Organization & & & Name, address, contact information. \\
\hline Person & & Client & Full name \\
\hline & $\begin{array}{c}\text { Employee of the Em- } \\
\text { ployment Center }\end{array}$ & Consultant & Card number \\
\hline Group of persons & & Group of the unemployed & List of identification numbers \\
\hline Document & & Application for informational service & List of requirements and restrictions \\
\hline & & Application for professional counseling & List of requirements and restrictions \\
\hline & & $\begin{array}{l}\text { Application for professional selection } \\
\text { ical System }\end{array}$ & List of requirements and restrictions \\
\hline Information services & Information search services & The database of registered unemployed & Access Protocols \\
\hline
\end{tabular}

Table 15. Relation of the process of professional orientation, informing and selection

\begin{tabular}{|l|l|}
\hline \multicolumn{1}{|c|}{ Title of the relationship } & \multicolumn{1}{c|}{ Connects the essence } \\
\hline Form an application for information & Client, Application for Professional Education or Counseling \\
\hline Form the application for selection & Organization, Application for professional selection \\
\hline Prepare information material & Consultant, Application, Information Material \\
\hline Pick a group according to the application & Consultant, Application for Professional Selection, Group of the unemployed. \\
\hline
\end{tabular}


Professional information and counseling can be made more effective if you take into account previous customer appearances and form their professional and psychological profile. This requires an additional analysis of the history of customer referrals and information about it from public sources and adds to the ontology new essences and relationships presented in Tables 16, 17.

Table 16. Contextual essences of processes of professional orientation and selection

\begin{tabular}{|l|l|l|l|}
\hline \multicolumn{1}{|c|}{$\begin{array}{c}\text { A group of Essences or a } \\
\text { general Essence }\end{array}$} & \multicolumn{1}{|c|}{ Subgroup } & \multicolumn{1}{|c|}{ Essence } & Customer profile \\
\hline Person & & Client & List of requirements and restrictions \\
\hline Document & & Application for informational service & List of requirements and restrictions \\
\hline & & Application for professional counseling & $\begin{array}{l}\text { Structure of requirements and psychophysiologi- } \\
\text { cal characteristics }\end{array}$ \\
\hline & & $\begin{array}{l}\text { EIAS - Unified Information and Analyti- } \\
\text { cal System }\end{array}$ & History of previous customer appeals \\
\hline Information services & Creating and maintaining a client profile & Protocols of interaction \\
\hline
\end{tabular}

Table 17. Contextual relations of processes of professional orientation and selection

\begin{tabular}{|l|l|}
\hline \multicolumn{1}{|c|}{ Title of the relationship } & \multicolumn{1}{c|}{ Connects the essence } \\
\hline Creating a client profile & Client, consultant, professional information request (or counseling). \\
\hline Prepare information material & Consultant, application, information material, history of previous applications, customer profile. \\
\hline
\end{tabular}

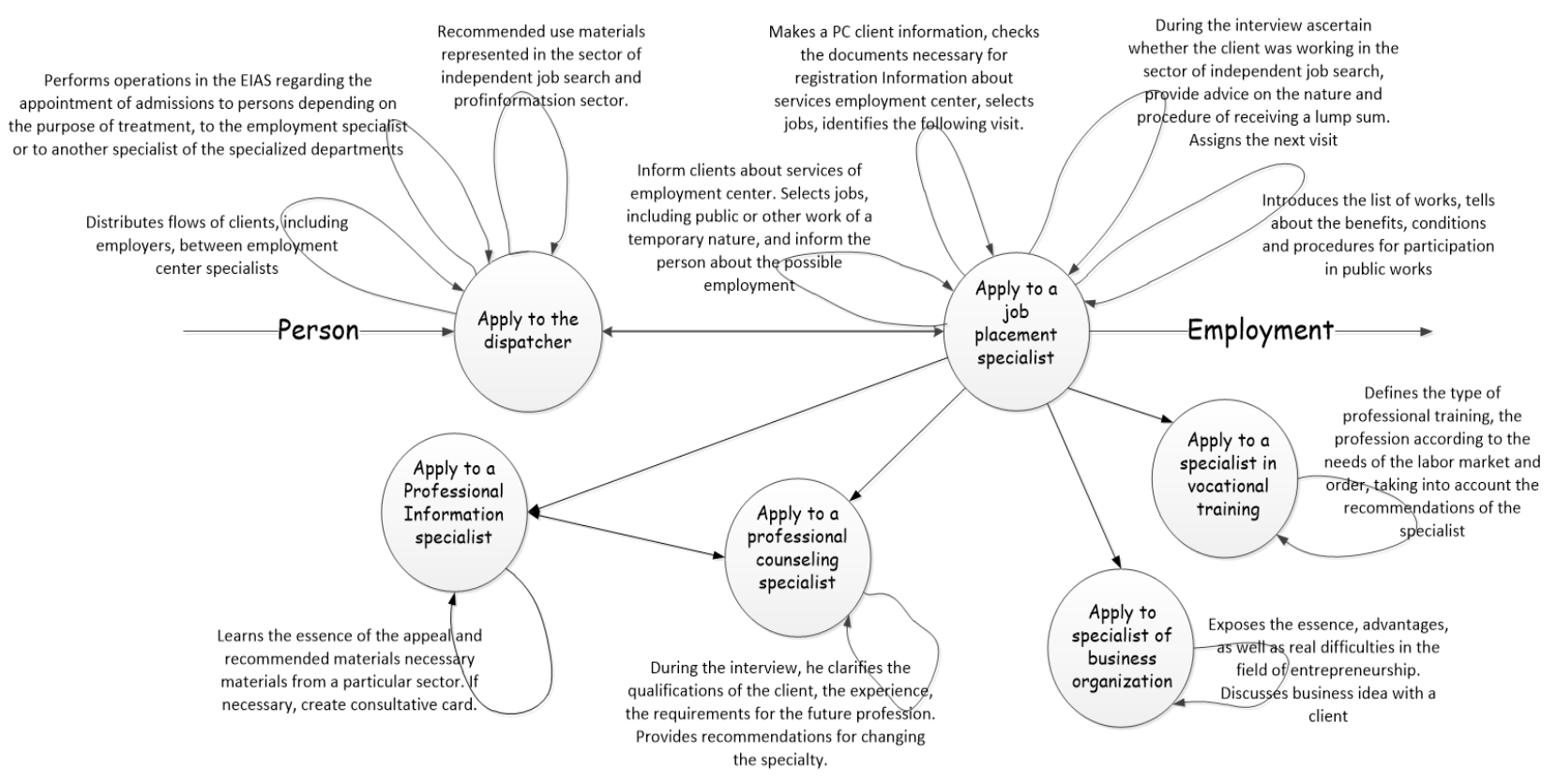

Fig.4. Context-dependent graph of employment processes

The process of employment with the employment service begins with a citizen's request for such a service with the assistance of finding suitable work. All citizens who are unemployed work, as well as those who want to change their place of work, get a job for a part-time or free time of study, have the right to apply for such a request. The services of the state employment service are provided to citizens free of charge.

As a result of an appeal of a citizen to the service of employment between them there is a legal relationship that gives rise to certain rights and obligations of both parties, as a consequence of which there are concrete actions in search of suitable work, which is clearly depicted in fig. 4 .

\section{CONCLUSIONS}

To successfully ensure the operation and development of an intellectual enterprise in the process of its construction, it is necessary to adhere to the hypotheses of the open world, that is, to allow for a constant change in the situation of the enterprise and its environment of work. For intelligent systems built on the basis of ontologies, this implies a constant adaptation and expansion of existing ontology.

At the same time, the quality of management decisions at an enterprise depends on the information available at the time of decision making. Additional information can 
be obtained by searching from open sources of the Internet, based on the context of the available data. To improve the quality of the solutions and expand the functionality, it is necessary to determine the method of obtaining relevant data from the context of business processes of the enterprise.

The proposed method of constructing an ontology based on the analysis of the context of situations is the development of methods for constructing it based on the analysis of business processes [8]. It is aimed at solving the problems of modification and expansion of the functional of the intellectual enterprise.

This method is also an expansion of the ontology construction method based on the analysis of typical tasks [11], but it focuses on the search for implicit information in the context of a task that allows it to improve the quality of its solution, account the new factors, or to change the process of solving the problem.

The developed method of constructing ontologies is based on the use of analysis of possible situations that arise during the execution of business operations. At the same time, the need to search for specific context data is determined by the need for the correct processing of the situation. Context data analysis can thus be used in intelligent systems with situational awareness to identify new situations and make decisions in known situations.

\section{REFERENCES}

[1] Quinn, J.B. The intelligent enterprise a new paradigm/ Quinn, J.B. //The Executive, 6(4).- 1992- pp.48-63.

[2] Markus J. Thannhuber. The Intelligent Enterprise: Theoretical Concepts and Practical Implications / Markus J. Thannhuber.- Physica Verlag.-2005. p.142.

[3] Ogiela, L. Cognitive systems for intelligent business information management in cognitive economy/ Ogiela, Lidia, and Marek R. Ogiela//International Journal of Information Management 34.6.- 2014.-pp 751-760.

[4] García-Martínez, Ramón. Information mining processes based on intelligent systems/ García-Martínez, Ramón, Paola Britos and Dario Rodríguez.//International Conference on Industrial, Engineering and Other Applications of Applied Intelligent Systems/.-Springer Berlin Heidelberg.- 2013.

[5] Melyara. Mezzi, Nadjia. Benblidia Study of Context Modelling Criteria in Information Retrieval - I.J. Information Technology and Computer Science, 2017, 3, 2839 Published Online March 2017 in MECS (http://www.mecs-press.org/) DOI:10.5815/ijitcs.2017.03.04

[6] Gruber T.R. A translation approach to portable ontology specification/ Gruber T.R. //Knowledge Acquisition, vol 5, 1993 - 199-220

[7] Salah Alkhafaji,B. Sriram Conceptualization and Integration of Information Systems in Educational Business Activities - I.J. Information Engineering and Electronic Business, 2013, 2, 28-33 Published Online August 2013 in MECS (http://www.mecs-press.org/) DOI: 10.5815/ijieeb.2013.02.05
[8] Y. Burov. Business process modelling using ontological task models./Burov Y//Econtechmod. - Lublin: Polish academy of sciences. - 2014. - №1. - P.11-23

[9] Olive, A. Conceptional Modeling of Information Systems. / Olive Antony. - Springer Berlin Heidelberg, 2007. - P. 471.

[10] Gómez-Pérez, Asunción. Ontology evaluation. /GómezPérez, Asunción //Handbook on ontologies.-Springer Berlin Heidelberg. - 2004. -pp. 251-273.

[11] Burov E. Complex ontology management using task models /Burov E//International Journal of Knowledgebased and Intelligent Engineering Systems. - Amsterdam: IOS Press. - 2014. - Vol 18, no 2. - P. 111-120.

[12] C.Toro. Building Domain Ontologies from Engineering Standards/ C.Toro, J.Vaquero, M.Grana, C.Sanin, E.Szczerbicki, J.Posada//Cybernetics and Systems: An International Journal.-2012.-pp.114-126.

[13] Bazire, M., July. Understanding context before using it. / Bazire, M., Brézillon P / Proceedings of International and Interdisciplinary Conference on Modeling and Using Context.- Springer Berlin Heidelberg, 2005.- P. 29-40.

[14] Prem Nath Context-Sensitive Grammars and LinearBounded Automata - I. J. Computer Network and Information Security, 2016, 1, 61-66 Published Online January 2016 in MECS (http://www.mecs-press.org/) DOI: 10.5815/ijcnis.2016.01.08

[15] Smirnov A.V. Models of Context-Managed Decision Support Systems in Dynamic Structured Regions / Smirnov A.V., Levashova T.V., Pashkin M.P. // Proceedings of SPIIRAN. - 2009. - №9. - P.116-147.

[16] Juan Ye. Situation identification techniques in pervasive computing: A review./Juan Ye, Simon Dobson, and Susan McKeever//Pervasive and Mobile Computing.- 2011

[17] I. Zavuschak, Z. Rybchak, I. Zheliznyak. Analysis of Clustering Algorithms - Advances in Soft Computing. Book Series of "Advances in Intelligent Systems and Computing", ISSN 2194-5357. Springer International Publishing AG 2017. Germany

[18] Kharchenko Y. Recommendations for servicing the population and employers by specialists of the employment service / Y. Kharchenko // State Employment Center. Kyiv 2014

[19] Usha Yadav, Gagandeep Singh Narula, Neelam Duhan, Vishal Jain Ontology Engineering and Development Aspects: A Survey - I.J. Education and Management Engineering, 2016, 3, 9-19 Published Online May 2016 in MECS (http://www.mecs-press.net) DOI: 10.5815/ijeme.2016.03.02

\section{Authors' Profiles}

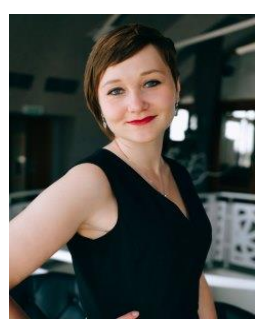

Iryna Zavuschak - a PhD-student, assistant of the Department of Information Systems and Networks, Institute of Computer Science and Information Technologies, of Lviv Polytechnic National University. Currently working on dissertation and engaged in scientific work. 


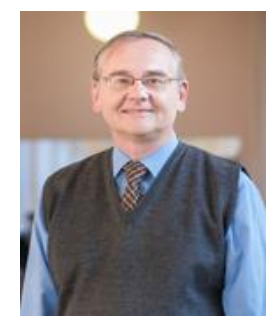

awareness
Eugene Burov - Doctor of Engineering Sciences, Professor of the Department of Information Systems and Networks, Institute of Computer Science and Information Technologies, Lviv Polytechnic National University. Research areas: distributed information systems and networks, cognitive and model-driven systems, situational

How to cite this paper: Iryna Zavuschak, Yevhen Burov, "The Context of Operations as the basis for the Construction of Ontologies of Employment Processes", International Journal of Modern Education and Computer Science(IJMECS), Vol.9, No.11, pp. 13-24, 2017.DOI: 10.5815/ijmecs.2017.11.02 